\title{
DOXA E CRENÇA ENTRE OS ANTROPÓLOGOS'
}

\author{
LYGIA SIGAUD
}

\begin{abstract}
RESUMO
Para explicar como uma interpretação se torna hegemônica e como se reproduzem os fenômenos de crença coletiva, o artigo centra foco na recepção do Ensaio sobre o dom, de Marcel Mauss, e dos diários de Malinowski. A comparação entre os casos permite examinar os fundamentos do crédito que se atribui a certos intérpretes, bem como a dinâmica da estruturação e da difusão de uma doxa.
\end{abstract}

PALAVRAS-CHAVE: doxa;Marcel Mauss; Malinowski; antropologia.

\section{SUMMARY}

In order to explain how an interpretation becomes hegemonic and how collective belief is reproduced, the article focuses on the reception of The Gift, by Marcel Mauss, and of Malinowski's diaries. By comparing both cases, it traces the origin of the credit attributed to certain interpreters, as well as the dynamics of dissemination of a doxology.

KEYWORDS: doxology; Marcel Mauss; Malinowski; anthropology.

[1] Uma versão preliminar deste texto foi apresentada em um seminário de pesquisa no Centre de Sociologie Européenne, em novembro de 2005 em Paris; no colóquio Rapports ambivalents entre sciences sociales européennes et américaines, em fevereiro de 2006 em Liège (Bélgica), e em aula inaugural ministrada no programa de pós-graduação em antropologia social da Universidade Estadual de Campinas (Unicamp), em março de 2006.Agradeço aos colegas presentes nos três eventos pelos comentários e pelas críticas, assim como a Federico Neiburg e Miguel Palmeira pela leitura cuidadosa desta versão ampliada.
Assim como ocorre em outras disciplinas, existem na antropologia interpretações tidas como evidentes por si mesmas, à maneira de uma doxa jamais questionada. As visões dominantes a respeito de o Ensaio sobre odom, de Marcel Mauss (1923-24), são um exemplo emblemático dessa espécie de senso comum na disciplina. Desde a década de 1960, antropólogos de diferentes tradições nacionais vêem no ensaio uma teoria da troca cujo princípio de explicação seria a identificação entre o espírito do doador e a coisa dada. Essa interpretação terminou por se impor como uma verdade a respeito do texto de Mauss, conforme atesta sua consagração, por exemplo, na biografia escrita por Marcel Fournier ${ }^{2}$ no verbete troca da Encyclopedia of social and cultural anthropology ${ }^{3}$. 
Tal interpretação contrasta fortemente com a dos contemporâneos de Mauss, a qual retinha do texto suas dimensões relativas ao direito, às obrigações e às prestações totais. Assim, em uma resenha escrita em 1927 para a Revue historique du droit français etétranger, Henry Lévy-Bruhl descreveu o Ensaio sobre o dom (doravante ED) como uma contribuição notável e muito útil para a história e a pré-história do direito. A história das obrigações, dizia então Lévy-Bruhl, poderia se beneficiar do estudo das sociedades inferiores4. O tema do direito também chamou a atenção de Bronislaw Malinowski: em uma carta de 1925, escreveu ter chegado a conclusões muito semelhantes às de Mauss ao trabalhar sobre problemas relativos ao direito5. A partir dos anos 1960, contudo, os antropólogos não mais se interessaram pelas análises de Mauss no que tangia ao direito e às obrigações. Apoiando-se sempre na mesma passagem do texto - referente à etnografia maori —, eles passaram a discutir a explicação mística das trocas no ED. Esse foi um fenômeno próprio apenas ao mundo dos antropólogos. Com efeito, entre historiadores que se inspiraram em Mauss, como Moses Finley ${ }^{6}$ Paul Veyne $^{7}$, bem como entre estudiosos da produção do grupo de Durkheim, como Paul $\operatorname{Vogt}^{8}{ }^{8}$, essa interpretação não foi levada em conta.

Qualquer texto, evidentemente, é passível de uma infinidade de leituras, e nenhum autor dispõe dos meios necessários para controlar as interpretações que serão feitas de seus escritos. As vicissitudes de Max Weber em relação às interpretações correntes de Aética protestante e o 'espírito' do capitalismo são um exemplo lapidar. Em 1910, cinco anos após a publicação original do trabalho, o sociólogo alemão ainda estava empenhado em replicar interpretações "pouco inteligentes e desonestas", mas não entretinha ilusões a respeito da eficácia de suas respostas. Weber achava que o público não leria seus comentários e que críticos como o historiador Felix Rachfahl teriam sempre a última palavra: "para pessoas que não conhecem bem o assunto", escrevia Weber, "será difícil crer que um professor universitário de história tenha podido, sobretudo com tamanha segurança, enganar-se completamente sobre a questão em debate em conseqüência de uma leitura totalmente superficial e de seu parti pris fundamental" 9 .

Desde a publicação, o ED foi objeto de interpretações diversas. Não se trata aqui de discuti-las, tampouco de tomar uma posição nos debates que elas suscitaram. Meu interesse incide sobre uma questão precisa: explicar e entender como uma interpretação, em meio a tantas outras disponíveis no mercado de idéias, pôde se tornar hegemônica. Para esse tipo de questão não se encontram respostas prontas nas intenções dos intérpretes. Eles tiveram suas razões ao propor certa interpretação, e o que estava em jogo nessas razões deve ser levado em conta e compreendido. Os intérpretes tampouco tiveram controle sobre os usos de seus escritos, e se suas interpretações de algum modo
[2] MarcelMauss.Paris:Fayard,1994.

[3] James Carrier. "Exchange". In: A. Barnard e J. Spencer. Encyclopedia of social and cultural anthropology. Londres/Nova York: Routledge, 1997 [1996].

[4] Ver Marcel Fournier, Marcel Mauss, p. 521 .

[5] Ver p.524.

[6] The word of Odysseus. Nova York: Viking Press, 1954.

[7] Le Pain et le cirque. Sociologie historique d'un pluralisme politique. Paris: Editions du Seuil, 1976.

[8] "Obligation and right: The Durkheimians and the sociology of law". In: Phillipe Besnard (org.).The sociological domain and the founding of French school. Cambridge/ Paris: Cambridge University Press/Éditions de la Maison des Sciences de l'Homme, 1983.

[9] "Réponse finale aux critiques". In: Sociologie des religions. Paris: PUF, 1996 [1910], p. 445. 
[1 o ] Para a primeira parte, retomei e remanejei uma análise precedente sobre o $E D$. Ver o artigo "As vicissitudes do 'Ensaio sobre o dom'”, publicado em Mana. Estudos de Antropologia Social, 5(2), 1999

[11] "Introduction".In: B. Malinowski. A diary in the strict sense of the term. Stanford: Stanford University Press, 1989 [1967], p.XVIII. se impuseram como dominantes no mercado de idéias foi porque houve quem estivesse disposto a lhes atribuir crédito. Trata-se, portanto, de examinar como se produzem e reproduzem tais fenômenos de crença coletiva. O caso do ED será o fio condutor e o objeto da primeira parte, a mais longa deste artigo. Nela, vou me concentrar no texto e em sua pré-história, no modo como ele foi recebido e usado pelos antropólogos, na explicação mística e em seu intérprete; finalmente, procurarei mostrar como essa interpretação se tornou hegemônica ${ }^{10}$. A fim de testar minhas hipóteses a propósito das condições sociais que favorecem os fenômenos de crença coletiva, na segunda parte vou analisar o caso de A diary in the strict sense of the term, de Bronislaw Malinowski. Publicado em 1967, quinze anos depois da morte do autor, esse texto, que Raymond Firth, em sua introdução, julgava ser tão-somente uma nota de pé de página na história da antropologia $^{11}$, tornou-se, a partir dos anos 1970, um argumento poderoso para legitimar outra modalidade de fazer antropologia, sobretudo entre antropólogos norte-americanos. A comparação entre os dois casos permitirá, na conclusão, um exame dos fundamentos do crédito que se atribui a certos intérpretes, bem como a dinâmica da estruturação e da difusão de uma doxa.

\section{UMA OBRA-PRIMA}

\section{Otexto em seu contexto}

Marcel Mauss publicou o ED aos 46 anos, quando ocupava a cadeira de História das Religiões dos Povos Primitivos e Não Civilizados da École Pratique des Hautes Études, em Paris. O texto de 134 páginas e quase quinhentas notas é composto de uma introdução, três capítulos e uma conclusão em três partes. Os fatos etnográficos são objeto dos dois primeiros capítulos. No terceiro, Mauss analisa o direito nas civilizações da Antiguidade. A conclusão se divide em conclusões morais, conclusões de sociologia econômica e de economia política e conclusões de sociologia geral e de moral.

O ponto de partida do ED é a constatação de que em numerosas civilizações as trocas e os contratos se fazem sob a forma de presentes, teoricamente voluntários, mas na realidade obrigatoriamente dados e retribuídos. Segundo Mauss ao principiar o texto, o trabalho era parte de um conjunto de estudos mais vastos dos quais o ED seria tãosomente um fragmento. Havia anos o autor se interessava pelo "regime do direito contratual e [pelo] sistema das prestações econômicas entre as diversas seções ou subgrupos de que se compõem as sociedades ditas primitivas, e também as que poderíamos chamar arcaicas". Mauss pretendia considerar apenas um traço de todos esses temas: "o caráter voluntário [...], aparentemente livre e gratuito, e no entanto 
obrigatório e interessado dessas prestações". O autor esclarecia ainda que seu estudo se deteria em somente um dos princípios que haviam conferido esse aspecto a uma forma necessária da troca e que o faria por meio de duas indagações: "Qual é a regra de direito e de interesse que, nas sociedades de tipo atrasado ou arcaico, faz que o presente recebido seja obrigatoriamente retribuído? Que força existe na coisa dada que faz que o donatário a retribua?"12. O objetivo era duplo: por um lado, chegar a conclusões arqueológicas sobre a natureza das transações humanas, sobre a moral e a economia dessas transações; por outro, mostrar como essa moral e essa economia funcionam ainda em nossas sociedades, e em seguida deduzir conclusões de ordem moral. Seu método consistia em servir-se da comparação precisa, estudando o assunto em áreas determinadas - Polinésia, Melanésia e Noroeste americano - e alguns direitos das civilizações da Antiguidade.

Estabelecer relação entre os fatos do Noroeste americano, da Polinésia e da Melanésia e os direitos arcaicos foi produto de um longo caminho percorrido por Mauss. Era notável seu controle de tudo o que se produzia na França, nos Estados Unidos, na Inglaterra e na Alemanha sobre o mundo primitivo, como atestam as setecentas resenhas que escreveu para os catorze primeiros volumes do Année Sociologique. Foi em 1910, por recomendação de Durkheim, que começou a se interessar pelos fatos do Noroeste americano, pelo potlatch descrito por Franz Boas: a destruição ritual das riquezas acumuladas para ofuscar o chefe rival. A princípio, acreditava que se tratava de uma instituição única no mundo. Em 1912, no entanto, Mauss tomou conhecimento da etnografia da Melanésia feita por Seligman e a partir daí identificou alhures a presença de instituições do tipo potlatch. Então ele já fala em sistemas de prestações totais, nos quais tudo se troca. Após a Primeira Guerra Mundial, retoma o estudo dos fatos melanésios. Em 1921, estabelece relação entre as formas de troca e contrato encontradas no Noroeste americano e na Melanésia, e antigos direitos indoeuropeus. Em 1922, põe-se a organizar as notas de Robert Hertz (seu colega, morto durante a guerra).É nessas notas que descobre a etnografia dos Maori feita por Eldson Best, a qual lhe permitiu identificar as três obrigações: dar, receber e retribuir. Em 1922, Mauss encontra a última peça do quebra-cabeça em Argonauts of Western Pacific, a monografia de Bronislaw Malinowskii3 sobre a instituição do kula (troca de braceletes e colares) entre os trobriandeses. Foi graças a esse livro que ele pôde se dar conta de todas as questões de prestígio e interesse que havia nas trocas ${ }^{14}$.

O plano do ED é inverso ao caminho percorrido por Mauss. O ensaio começa pelo estudo dos fatos da Polinésia: as prestações totais não agonísticas. Mauss analisa o conceito de hau, o espírito do doador que permanece na coisa dada e que obriga quem a recebeu a retribuí-
[12] "Essai sur le don. Forme et raison de l'échange dans les sociétés archaiques". Sociologie et Anthropologie. Paris: PUF 1991 [1923-24], pp. 147 e 148 .
[13] Argonauts of Western Pacific. Londres/ Nova York: G. Routledge \& Sons Ltd./ E.P. Dutton \& Co.

[14] Para esta reconstituição do percurso rumo ao $E D$, apoiei-me nos programas de curso de Mauss, em suas conferências e nas notas que redigiu no período. Ver Marcel Mauss. Oeuvres 3. Cohésion sociale et divisions de la sociologie. Paris: Minuit,1969, vol. III, pp. 34-77. 
[15] "Essaisurledon", pp. 266 e267.

[16] Marcel Fournier.Marcel Mauss, pp. 524-5.

[17] Crime and custom in savage society. Londres: Routledge \& Kegan Paul, Ltd., 1970 [1926],p. 41. la. O conceito é tratado por Mauss como uma das idéias centrais do direito maori. No segundo capítulo, são analisadas as prestações totais agonísticas, e para isso o autor se vale dos dados relativos ao kula e ao potlatch. Aqui estão em jogo os conflitos, o lugar na hierarquia, as ambições de prestígio e poder envolvidas nas trocas. No terceiro capítulo, Mauss compara as instituições primitivas e os direitos arcaicos de modo a pôr em evidência a oposição entre sociedades como as nossas, que distinguem os direitos sobre as coisas dos direitos sobre as pessoas, e as sociedades primitivas e as civilizações antigas, nas quais essa distinção não é feita. Em suas conclusões, Mauss consagra a primeira parte a considerações de ordem moral. Depois de haver sublinhado a permanência do dom, da liberdade e das obrigações nas nossas sociedades, defende - no que é uma intervenção em debates da época - a incorporação da moral do dom ao "nosso" direito. $\mathrm{Na}$ segunda parte da conclusão, Mauss examina as implicações dos fatos estudados para a análise de fatos econômicos gerais. Trata-se, por um lado, de implodir, assim como o fez Malinowski, as doutrinas correntes a respeito da economia "primitiva" e de ir adiante: dissolver e dar outra definição às noções que ele próprio utilizou (como dom e presente), pois são inexatas. Por outro lado, de pôr em questão os conceitos do direito e da economia freqüentemente opostos, tais como liberdade e obrigação, liberalidade e generosidade, luxo e poupança, interesse e utilidade ${ }^{15}$. Mauss termina o ensaio com observações de método e fixando os limites de sua empreitada. Diz que não estava propondo um modelo: o trabalho era indicativo e estava incompleto; visava à formulação de questões para historiadores eetnógrafos, assim como a sugestão de objetos de pesquisa; não pretendia nem resolver um problema, nem fornecer uma resposta definitiva.

O ensaio teve acolhida favorável por parte de antropólogos reconhecidos, como Malinowski na Inglaterra e Franz Boas nos Estados Unidos, mas foi duramente criticado por Henri Hubert, amigo e colaborador de Mauss, que, em carta de 1925, apontou especialmente a falta de precisão da noção de prestações sociais totais ${ }^{16}$. Em 1926 , Malinowski publicou Crime and custom, livro cujo tema é o direito e a ordem nas sociedades primitivas. Suas questões são muito próximas àquelas formuladas no $E D$, ou seja, referem-se às regras do direito que asseguram o cumprimento das obrigações. Malinowski dedicou a Mauss apenas uma nota de pé de página para reconhecer que o colega francês tinha razão ao lembrar que não existiam dons gratuitos ${ }^{17}$. Em 1929, o ED foi objeto de uma crítica de Raymond Firth em seu livro sobre a economia dos Maori. Firth, que estudara economia na Nova Zelândia, fizera o doutorado na Inglaterra sob orientação de Malinowski. Sua tese apoiava-se na literatura disponível, pois não havia feito trabalho de campo. A principal crítica ao $E D$ dizia respeito ao 
conceito de hau, que, segundo Firth, não se referia ao espírito do doador, mas ao espírito da coisa ${ }^{18}$. Como seu estudo era sobre os Maori, Firth se interessou somente pelas passagens do $E D$ que se ocupavam desse povo da Polinésia e superestimou a importância dos dados maoris no texto. $\mathrm{O}$ autor diz, por exemplo, que esses dados são centrais para a teoria geral da reciprocidade de Mauss ${ }^{19}$. Ora, o vocábulo reciprocidade nem sequer faz parte do léxico do artigo do Année Sociologique: há referência apenas a dons recíprocos, o que não corresponde ao conceito de reciprocidade. E autor do ED em parte al guma escreve que está a elaborar uma teoria da reciprocidade - a única teoria mencionada é a das três obrigações. Mauss não respondeu a Firth. A rigor, deixou de lado o tema das trocas e do contrato. Seu interesse principal eram os rituais e as representações religiosas. Em 1930, no memorial escrito por Mauss para o ingresso no Collège de France, o ED era visto como não mais que um momento em seu percurso ${ }^{20}$.

Entre 1930 e 1940, os textos de Mauss e os que escrevera com Hubert circulavam e eram lidos na Inglaterra - nos cursos da London School of Economics (LSE), principal centro de antropologia da época - e nos Estados Unidos - nas universidades de Chicago e Berkeley ${ }^{21}$. Robert Lowie, professor em Berkeley e antropólogo de renome, compartilhava o interesse dos colegas de Londres pelos trabalhos de Mauss e Hubert. Em sua história do pensamento antropológico, são esses os únicos colaboradores de Durkheim a figurar no capítulo sobre a sociologia francesa. Lowie via o $E D$, para o qual já chamara a atenção como uma contribuição ao estudo da hierarquia, como um exemplo acabado da metodologia de Durkheim. Além disso, sublinhava o caráter obrigatório do dar e do receber, assim como a idéia de prestações totais. ${ }^{22}$

Os estudiosos que na década de 1930 publicaram sobre o tema da troca não voltaram a Mauss. Malinowski, por exemplo, retomou a problemática das obrigações em seu Coral gardens ${ }^{23}$ sem fazer referência ao ED. O antropólogo vienense Richard Thurnwald também não o cita, como assinala Juillerat ${ }^{24}$. De fato, a problemática não era a mesma: Thurnwald se interroga sobre a origem da reciprocidade, percebida como relações simétricas, enquanto para o autor doED o que importava era identificar a regra de direito e de interesseque faz com que o presente recebido seja obrigatoriamente retribuído. Além disso, Thurnwald buscava resposta em mecanismos biopsíquicos, uma espécie de relação causal que daria calafrios aos discípulos de Durkheim. O que importa destacar é que o ED não era referência obrigatória à época.

\section{A explicação mística e seu intérprete}

Na segunda metade da década de 1940, o ED haveria de ser destacado como uma descoberta da "idéia fundamental da reciprocidade",
[18] Economics of the New Zealand Maori. Wellington, Nova Zelândia: R. E. Owen. Government Printer, 1959 [1929].

[19] Ver p.421.

[20] Marcel Mauss, "L'oeuvre de Marcel Mauss par lui-même", Revue Française de Sociologie, $\mathrm{XX}(1)$, janeiromarço.

[21] Vejam-se a esse respeito os programas de curso da LSE (The calendar of the LSE.1937-38;1938-39;1947-48); Firth ("An appraisal of modern social anthropology". Annual Review of Anthropology, vol.4, 1975, p.2) e Fournier (Marcel Mauss, pp. 634-5).

[22] Histoire de l'ethnologie classique. Paris: Payot, 1971 [1937] e Traité de sociologie primitive. Paris: Payot, 1969 [1936],pp.193-6.

[23] Coral gardens and their magic. Londres: George Allen \& Unwin Ltd., 1935.

[24] "Richard Thurnwald et la Mélanesie. Réciprocités, hiérarchies, évolutions". Gradhiva: Revue d'Histoire et d'Archives del'Anthropologie, n.14,1993. 
[25] "La sociologie française". In: Gurvitch, G. (org.). La sociologie au $X X{ }^{e}$ siècle. Paris: PUF, 1947, p.20.

[2 6] Paris:Mouton, 1967 [1949],p. 61

[2 7] Ver pp.XI-XII.

[2 8] Ver p. 61

[29]Verp.99. no balanço que então fez o etnólogo Claude Lévi-Strauss da sociologia francesa no século XX ${ }^{25}$. No final da década, quando Marcel Mauss já se encontrava doente e afastado das atividades intelectuais, seu $E D$ foi invocado pelo mesmo autor como um trabalho "admirável", "clássico" e fonte de inspiração para explicar as trocas matrimoniais por meio do que Lévi-Strauss denominava princípio de reciprocidade. Essa referência está inscrita no livro Les Structures elémentaires de la parentéé, originalmente a tese de doutorado do autor, elaborada com base em pesquisa em bibliotecas norte-americanas e defendida em $1948 \mathrm{em}$ Paris. O trabalho tinha a ambição de formular uma teoria geral dos sistemas de parentesco e adotava como método, segundo Lévi-Strauss, uma espécie de combinação do procedimento de examinar exemplos extraídos de diferentes contextos, como o havia feito Frazer, com o de limitar-se ao estudo dos fatos no próprio contexto, ao estilo de Durkheim. Também quanto a essa escolha metodológica, o autor reivindicava uma inspiração maussiana ${ }^{27}$. Lévi-Strauss abre o quinto capítulo, intitulado "O princípio da reciprocidade", com uma referência às conclusões do $E D$ :

Mauss propôs-se mostrar primeiramente que a troca se apresenta nas sociedades primitivas menos em forma de transações que de dons recíprocos, e em seguida que estes dons recíprocos ocupam um espaço muito mais importante nessas sociedades que na nossa. Finalmente que esta forma primitiva das trocas não tem somente, nem essencialmente, caráter econômico, mas coloca-nos em face do que chama, numa expressão feliz, "um fato social total", isto é, dotado de significação simultaneamente social e religiosa, mágica e econômica, utilitária e sentimental, jurídica e moral 28.

Lévi-Strauss pára por aí, não retornando mais ao texto de Mauss. Nessa parte do livro, menciona ainda sociedades em que havia a troca por meio de dons recíprocos e detém-se no exemplo da Polinésia, nos Maori, referindo-se a Best (a fonte de Hertz) e ao livro de 1929 de Raymond Firth, mas não à crítica deste a Mauss. Ao longo do capítulo, o autor formula a tese de que os fenômenos da troca se inscrevem em um mesmo complexo fundamental da cultura. Mais adiante, no sétimo capítulo, desenvolve a teoria de que a origem desses fenômenos, assim como da proibição do incesto, das regras de exogamia e das organizações dualistas, residiria nas "estruturas fundamentais do espírito humano", cuja universalidade ele reivindica. Tais estruturas seriam a exigência da regra como regra; a noção de reciprocidade e o caráter sintético do dom ${ }^{29}$.

Mauss morreu em 1950. Para homenageá-lo, o sociólogo francês Georges Gurvitch organizou uma coletânea de textos na qual figurava o $E D$ e convidou Lévi-Strauss para escrever a introdução. Era a 
segunda vez que lhe confiava um trabalho: o primeiro havia sido o balanço referente à sociologia francesa acima mencionado. Os dois conheciam-se de Nova York. Lá haviam se refugiado durante a Segunda Guerra Mundial e atuado como professores da Escola Livre de Altos Estudos. Em 1950, ambos reivindicavam a herança maussiana e estavam empenhados em reabilitar, via Mauss, a Escola Sociólogica francesa no ambiente hostil ao durkheimianismo do pós-guerra na França ${ }^{30}$. Em vida, Mauss não publicara nenhum livro, e seus trabalhos encontravam-se dispersos em periódicos, notadamente no Année Sociologique. A coletânea se inscrevia, portanto, em um projeto de editar sua obra.

Lévi-Strauss inicia sua "Introdução" a Sociologie et anthropologie ${ }^{31}$ com um elogio a Mauss: diz que poucos pensadores tiveram tamanha repercussão na França e refere-se aos "ecos duráveis" que sua obra teria alcançado no exterior entre figuras como Malinowski, RadcliffeBrown, Firth e Evans-Pritchard, na Inglaterra; Redfield, Herskowitz e Lloyd Warner, nos Estados Unidos. Na França, a influência maussiana havia se produzido mais pela via do contato regular ou ocasional com colegas e discípulos, e, fora da França, mais por meio do acaso de um encontro ou uma leitura do que diretamente pelos escritos. Com isso, Lévi-Strauss instituiu o contato pessoal como critério para legitimar a pretensão a intérprete autorizado: só os que conheceram e escutaram Mauss - e implicitamente ele se considera um deles - estavam em condições de avaliar a fecundidade da obra do autor e fazer um balanço. Em seguida, dá início a seus comentários.

O pensamento de Mauss é caracterizado como "denso" e "esotérico", "atravessado de cintilações" e dado a "caminhos tortuosos" que o afastavam do itinerário que o conduziria ao "núcleo dos problemas". Lévi-Strauss anuncia que vai destacar na obra alguns "aspectos" e coloca em evidência o caráter precursor dos escritos de Mauss, desde as primeiras páginas apresentado como uma espécie de profeta que teria se antecipado a uma série de desenvolvimentos ulteriores da antropologia. Dentre o conjunto de seis textos reunidos na primeira edição de Sociologie et anthropologie, Lévi-Strauss detém-se mais longamente no ED: dedica-lhe 16 das 43 páginas da "Introdução". O trabalho é apresentado como um texto "capital", o "mais justamente célebre", aquele cuja influência foi mais profunda ${ }^{32}$, "um evento decisivo da evolução científica”, uma obra-prima. Tantas honrarias o ED jamais recebera em sua saga, que começara nos anos 1920.

O "aspecto" do ED a ser exploradoé a "revolução" que Mauss teria operado. Segundo Lévi-Strauss, "pela primeira vez na história do pensamento etnológico, um esforço era feito para transcender a observação empírica e atingir realidades mais profundas". A "descoberta" atribuída ao autor passa então a ser louvada: teria aberto novas
[30] Sobre a reivindicação da herança maussiana, ver Karady ("Présentation”. In: Marcel Mauss. Oeuvres. 1. Les Fonctions sociales du sacré. Paris: Les Éditions de Minuit, 1968, pp. IVI), e Fournier (Marcel Mauss, pp. 760-6). É Karady quem chama a atenção para o fato de que a preocupação em reabilitar a Escola via Mauss teria funcionado como critério na seleção dos textos incluídos na coletânea. Assim, só foram escolhidos textos da "maturidade" de Mauss e deixados de lado outros mais conformes à ortodoxia durkheimiana, provavelmente para tornar o ensinamento da escola mais aceitável ao gosto da época (p.V).

[31] Claude Lévi-Strauss. "Introduction à l'oeuvre de Marcel Mauss". In: Marcel Mauss.Sociologie et anthropologie. Paris: PUF 1991 [1950].

[32] Claude Lévi-Strauss. "Introduction à l'oeuvre de Marcel Mauss", p.XXIV. 
[33] Ver pp.XXXIII-XXXVI.

[34] Ver p.XXXVIII.

[35] Os negritos correspondem às supressões. Ver Marcel Mauss, “Essai surle don", p. 214. possibilidades metodológicas, como aquelas exploradas por Firth com a análise dos "ciclos de reciprocidade" entre os Tikopia; estaria próxima das descobertas, também metodológicas, feitas por Troubetzskoy e Jakobson para a lingüística estrutural; sua relevância seria equivalente à da descoberta da fonologia para a lingüística; o texto teria, enfim, inaugurado "uma nova era para as ciências sociais", e sua importância seria comparável àquela da descoberta da análise combinatória para a matemática moderna. Embora Mauss não houvesse explorado a própria descoberta, sua intuição estava correta. Como prova, Lévi-Strauss apresenta outra descoberta, mais recente no domínio do parentesco, de "regras precisas segundo as quais se constituem, em qualquer tipo de sociedade, ciclos de reciprocidade cujas leis mecânicas são doravante conhecidas, possibilitando o emprego do raciocínio dedutivo num domínio que parecia submetido ao arbítrio mais completo"33. Não há autocitação, mas não é difícil reconhecer nessa passagem a teoria desenvolvida pelo autor em 1949. Assim, a justeza da reflexão de Mauss estaria no desenvolvimento que ele, o comentador, teria dado ao seu achado.

Foi então que Lévi-Strauss ofereceu uma explicação para o fato de Mauss não ter explorado sua própria descoberta, comparando o mestre ao profeta Moisés, que não logrou conduzir seu povo à Terra Prometida. Mauss teria a certeza lógica de que a troca é um denominador comum de grande número de atividades humanas. A observação empírica não lhe permitia ver a troca nos fatos, mas tão-somente as obrigações de dar, receber e retribuir. A "teoria”, afirma Lévi-Strauss, exigia uma estrutura. Não fica claro no entanto de que teoria se trata, nem é possível localizar no $E D$ uma preocupação dessa natureza. A solução encontrada por Mauss para o problema que lhe atribui o comentador foi aplicar "uma fonte de energia que opere sua síntese" 34 . Segue-se então uma citação do ED: "Pode-se [...] provar que nas coisas trocadas [...] há uma virtude que força as dádivas a circularem, a serem dadas e retribuídas". O que é suprimido da citação, feita sem referência às páginas correspondentes, permitiria ao leitor identificar o contexto original da formulação. Trata-se da conclusão da parte referente ao Noroeste americano, na qual Mauss analisa o potlatch. Eis a citação completa: "Podemos ainda levar mais longe a análise e provar que, nas coisas trocadas no potlatch, há uma virtude que força as dádivas a circularem, a serem dadas e retribuídas". E prossegue Mauss: "Em primeiro lugar, pelo menos os Kwakiult e os Tsimshian fazem, entre os diversos tipos de propriedades, a mesma distinção que os romanos ou os trobriandeses e os samoanos. Para eles [...]"35. Embora não esteja em jogo fazer uma exegese do $E D$, não se pode concluir que Mauss aí estivesse resolvendo o problema teórico formulado por Lévi-Strauss. Ele está apenas apresentando uma concepção nativa 
e relacionando-a com outras concepções nativas e com as encontradas nos direitos antigos. Prosseguindo com o raciocínio do comentador: escreve ele em seguida que, como a virtude da coisa não está na coisa, mas é concebida subjetivamente, ou bem essa virtude não é outra coisa senão o próprio ato da troca, ou bem é de uma natureza diferente e, em relação a ela, o ato da troca se torna um fenômeno secundário. O único modo de escapar ao "problema" teria sido perceber que é a troca que constitui o fenômeno primitivo, e não as operações discretas nas quais a vida social a decompõe. Mauss teria procurado restituir o todo com suas partes, porém, como isso seria impossível, teria então acrescentado uma quantidade suplementar. Essa quantidade seria o hau. "Não estamos aqui diante de um desses casos (não tão raros) em que o etnólogo se deixa mistificar pelo nativo?"36 "O hau não é a razão última da troca:é a forma consciente sob a qual homens de uma sociedade determinada, em que o problema tinha uma importância particular, conceberam uma necessidade inconsciente cuja razão está alhures". Também aqui não há nenhuma citação do $E D$, nem ao contexto no qual Mauss se referiu ao hau e aos juristas maoris, tratados por Lévi-Strauss como "sábios". Graças a essa técnica argumentativa, o hau, que aparecia em Mauss como uma noção central do direito maori, torna-se, com Lévi-Strauss, a explicação da troca. Foi esse "equívoco" que impediu que Mauss chegasse à "terra prometida", tal como Moisés. Aqui a "terra prometida" seria a percepção de que a 'realidade subjacente' à troca só pode ser encontrada nas estruturas mentais inconscientes, que podem ser atingidas através das instituições e sobretudo da língua"37.

Lévi-Strauss tinha 42 anos quando publicou sua "Introdução". Após uma estada quase ininterrupta de seis anos em Nova York, havia regressado a Paris em fins de 1947, disposto a iniciar a carreira universitária. Até então, na França, só tinha sido professor do ensino secundário. Sua iniciação no magistério superior se dera no Brasil (1935-38), na recém-criada Universidade de São Paulo (USP). Durante a guerra, Lévi-Strauss voltou a lecionar, desta vez nos Estados Unidos. Quando lá estava, não lhe faltaram convites para trabalhar em prestigiosas universidades norte-americanas: recusou todos porque ambicionava exercer sua profissão na França $3^{8}$. Para um outsider autodidata - que vinha da filosofia, não estudara etnologia e, apesar do campo feito no Brasil e da publicação de alguns artigos que lhe valeram o reconhecimento como americanista ${ }^{39}$, era visto como um antropólogo de gabinete $4^{\circ}$ - , havia, portanto, todo um caminho a percorrer para inserirse no establishment científico francês. Por ocasião do regresso, pede a Georges Davy, colaborador de Mauss e então titular da cátedra de Sociologia na Sorbonne, que se torne seu orientador, para que possa defender a tese defendida nos Estados Unidos41. Em 1948, foi
[36] Ver p.XXXVIII.

[37] Ver p.XXXIX.

[38] Annie Cohen-Solal. "Claude Lévi-Strauss aux Etats-Unis: Des portes donnant accès à d'autres mondes et à tous les temps". Critique, LV, 1999, p. 25 .

[39] F. Peixoto. "Lévi-Strauss no Brasil: A formação do etnólogo". Mana: Estudos de Antropologia Social, vol. 4, n. 1., 1988, pp. 81-7.

[40] F. Héritier. "La Citadelle imprenable". Critique, T.LV., n.620-621, 1999, p.63.

[41] Claude Lévi-Strauss e Didier Eribon.De prèset de loin, p. 76 . 
[42] Ver p. 80.

[43] Em entrevista concedida vinte anos após o episódio, Lévi-Strauss refere-se a este sentimento (C. Clément e D. A. Grisoni. "Lévi-Strauss: autoportrait". Magazine Littéraire n. 58 , nov. 1971, p. 24).

[44] Como observa Bertholet, o fato de ocupar um lugar na antropologia americana conferia-lhe prestígio e um peso considerável na França, mas não lhe assegurava posição institucional. Para tanto, Lévi-Strauss precisava "se situar na tradição etnológica francesa". "É por isso que ele acrescenta às referências americanas uma série de nomes franceses. Marcel Mauss, claro." (D. Bertholet. Claude Lévi-Strauss. Paris: Plon, 2003, p.173.)

[45] Homo academicus. Paris: Les Editions de Minuit, 1984 nomeado maître de recherche no Centre National de la Recherche Scientifique(CNRS), "um posto de espera" ${ }^{2}$, e, em seguida, subdiretor do Musée de l'Homme. No ano seguinte, apoiado pelo historiador Lucien Febvre, que conhecera em 1935 quando estivera em missão na USP, passou a dar seminários na École Pratique des Hautes Études (seção VI). Graças a Georges Dumézil, outro colaborador de Mauss, foi indicado para diretor de Estudos da École Pratique des Hautes Études (seção V, de Ciências Religiosas) e assumiu a cátedra de História das Religiões dos Povos Primitivos e Não Civilizados, que Mauss ocupara entre 1901 e 1940. Em pouco tempo, portanto, Lévi-Strauss logrou se inserir no mundo universitário francês com o apoio de pessoas próximas a Mauss, as quais viam nele um herdeiro "natural" do mestre. Em 1949, apresentou sua candidatura à cadeira de Sociologia Comparada do Collège de France e não foi aceito. Em 1950 reapresentou-se e foi novamente derrotado. As duas candidaturas, assim como o sentimento de que após a segunda derrota sua carreira havia sido liquidada43, constituem forte indício de que tinha ambições elevadas, de que desejava chegar ao topo da hierarquia de prestígio, reconhecimento que lhe teria sido assegurado caso houvesse sido eleito para o Collège de France.

Em virtude do interesse em inserir-se no mundo acadêmico francês, Lévi-Strauss tinha de inscrever-se na trilha aberta por Mauss, o grande nome da etnologia na França. Essa era a modalidade apropriada para ser ouvido naquele mundo, ser reconhecido como pare obter posições nas instituições universitárias ${ }^{44}$. Nos escritos de 1946 e 1949, Lévi-Strauss homenageava Mauss e não lhe fazia nenhuma crítica. Mesmo não compartilhando o ponto de vista de Mauss — tanto no que se refere ao método (valer-se de exemplos retirados de diversas províncias etnográficas) como no que se relaciona ao tratamento dado às trocas (uma manifestação de regras do inconsciente, do princípio de reciprocidade) - , nosso personagem fez o que deveria ser feito ao escrever sua obra sobre o parentesco: apresentou-se como seguidor do mestre. Para avançar na carreira e galgar ao topo deveria seguir ajustando-se ao modo de funcionamento do mundo acadêmico francês: era preciso distinguir-se de Mauss, ir além do mestre para lograr aumentar o valor de seu próprio "nome", que, como o assinala Pierre Bourdieu45, é o bem mais precioso do mundo acadêmico. Com a sua "Introdução", Lévi-Strauss novamente fez o que deveria ser feito: consagrou o $E D$, conferindo-lhe um valor que até então não lhe tinha sido atribuído, e em seguida apontou o "erro" que lhe permitia fazer avançar sua própria teoria e com isso superar Mauss. Se tivesse escolhido inserir-se no mundo acadêmico de outro país, Lévi-Strauss talvez pudesse ter desenvolvido sua própria teoria e dispensado as reverências a Mauss e a busca de seus "erros". 
A comparação com o caso do antropólogo britânico Edmund Leach pode ser esclarecedora nesse sentido. Como o colega francês, Leach iniciou a carreira nos anos 1940. Defendeu a tese de doutorado na London School of Economics, aos 37 anos, em 1946. No ano seguinte foi incorporado à equipe da mesma instituição como lecturer. Em 1951, escreveu um ensaio sobre parentesco com críticas devastadoras a Radclife-Brown, Meyer Fortes, Evans-Pritchard e LéviStrauss ${ }^{46}$. Recebeu por esse ensaio o Curl Prize, concedido pelo Royal Anthropological Institute e atribuído por um júri do qual participava Meyer Fortes, um de seus alvos, algo impensável no mundo acadêmico francês.Após esse episódio, Leach foi convidado a integrar a Faculdade de Antropologia e Arqueologia da Universidade de Cambridge pelo mesmo Meyer Fortes. Em 1954, publicou uma monografia sobre os Kachin, na qual não se apoiava na teoria de nenhum colega e usava seu material para colocar por terra as idéias bem estabelecidas dos membros do establishment da antropologia social britânica47. Raymond Firth, um dos autores criticados nesse livro, redigiu o prefácio, o que seria ainda altamente improvável no universo francês. Ao longo da carreira universitária, Leach cultivou a representação de si mesmo como "herético" e foi um crítico implacável das teses dos colegas dos quais discordava. Tornou-se um grande "nome" da antropologia social britânica, sem precisar render homenagens nem poupar críticas aos colegas. Foi ainda provost do King's College, na University of Cambridge, com o apoio de seus pares, e feito Sir do Império Britânico pela rainha Elizabete II. Se o confronto permanente não lhe prejudicou a carreira, isso se deve às particularidades do modo de funcionamento do mundo acadêmico britânico. Leach não esteve sujeito às coerções que se abateram sobre Lévi-Strauss para lograr construir um "nome" na França ${ }^{4}$.

\section{A maorisação do ED}

A crítica de Lévi-Strauss a Mauss não produziu efeitos imediatos: salvo pelos comentários de filósofos, como Claude Lefort 49 e Merleau Ponty5o, não seria exagero dizer que permaneceu ignorada por algum tempo.

No volume do Année Sociologique de 1951, Henry Lévy-Bruhl escreveu o "In memoriam" a Marcel Mauss, citou a publicação do Sociologie et anthropologie, mas não a "Introdução". O ED foi então mencionado, dentre outros textos "célebres" do autor, como um trabalho que havia aberto importantes perspectivas sobre a gênese do direito e da economia política ${ }^{51}$. No mesmo volume foram publicados dois artigos referidos a Mauss e ao ED. Um é da autoria de Émile Benveniste, para quem o grande mérito de Mauss foi ter demonstrado a relação funcional entre o dom e a troca, e definido, por meio dessa relação, um
[46] "The structural implications of matrilineal cross-cousin marriage". Journal of the Royal Anthropological Institute, n. 81,1951.

[47] Political systems of highland Burma. Boston: Beacon Press, 1967 [1954].
[4 8] As referências a Leach se apóiam em trabalho anterior (L. Sigaud, "Apresentação".In: E. Leach.Sistemas políticos da Alta Birmânia. São Paulo: Edusp, 1996), no qual analisei a sua posição singular no campo da antropologia social britânica.

[49] Claude Lefort. "A troca e a luta doshomens". In:Escobar,C.H.:O método estruturalista. Rio de Janeiro: Zahar Editores, 1967 [1951],pp. 64-79

[50] Maurice Merleau-Ponty. "De Mauss à Lévi-Strauss". Signes. Paris: Gallimard, 1960,pp.143-57.

[51] "In memoriam. Marcel Mauss". Année Sociologique. Troisième Série (1948-49), 1951. 
[52] "Don et échange dans le vocabulaire indo-européen". Année Sociologique. Troisième Série (1948-49), 1951, pp. 7 e 8.

[53] "Droit et predroit en Grèce Ancienne". Droitet Institution en Grèce Ancienne. Paris: Flammarion, 1982 [1951],pp.11-2.

[54] "Une science en devenir". L'Arc, n. 48,1972 [1952], p. 8.

[55] E. Evans-Pritchard. "Introduction à 'L'Essai sur le don'”, L'Arc, n. 48,1972 [1954].

[56] The Maoriand his religion in its nonritualistic aspects. Copenhague: Ejnar Munksgaard,1954,p.115, nota 75

[5 7] Ver pp. 117-9.

[58] Economics of the New Zealand Maori.

[59] Primitive Polynesian Economy. Londres: Routledge \& Keagan Paul, 1965[1939], pp.331-2.

[6o ] "Review of M. Mauss The Gift". Man, 55 (30), 1955.

[61] "Some principles of exchange and investment among the Tiv". American Anthropologist, 57 (1), pp. 6o-70, 1955.

[62] Claude Lévi-Strauss. The formative years. Cambridge, Cambridge University Press, 2003, p. 175. conjunto de fenômenos religiosos, econômicos e políticos das sociedades arcaicas. Ao longo do texto o lingüista procura explorar os elementos que no vocabulário das línguas indo-européias iluminam a pré-história das noções de dom e troca ${ }^{2}$. O segundo artigo, de Louis Gernet, é dedicado ao estudo dos direitos mediterrâneos da Antiguidade, notadamente das sociedades helênicas. Também aí se trata de levar adiante as pistas do $E D$ e examinar representações religiosas e comportamentos nos quais seja possível buscar os antecedentes de um pensamento jurídico53.

Em 1952, por ocasião de conferência pronunciada em Oxford, onde se encontrava como professor visitante, o antropólogo francês Louis Dumont ressaltou a importância da “Introdução" para entender o impacto da obra de Mauss na antropologia contemporânea ${ }^{54}$. Não se refere, no entanto, aos supostos "erros" de Mauss. Dois anos mais tarde, Evans-Pritchard redigiu o "Prefácio" à primeira tradução inglesa do $E D .{ }^{55} \mathrm{~A}$ "Introdução" de Lévi-Strauss aí figura, ao lado do "In memoriam" de Henry Lévy-Bruhl, como exemplo de análise da contribuição de Mauss ao pensamento sociológico na França. Também aqui nenhuma palavra sobre os equívocos contidos no $E D$. Ainda em 1954, J. P. Johansen publica em Copenhague um livro sobre os Maori. $O E D$ é citado como um texto que oferece reflexões finas e indiscutíveis a respeito da troca. O autor, contudo, faz duas ressalvas: a primeira diz respeito à tradução de um provérbio maori $5^{6}$ e a segunda ao conceito de hau, que, segundo ele, apresentaria muito mais dificuldades do que Mauss percebera 57 . Não há referência a Lévi-Strauss. Cinco anos mais tarde, Raymond Firth ${ }^{8} 8$ reedita seu livro de 1929 sobre a economia maori e não leva em conta a crítica de Lévi-Straus a Mauss; em 1965 publica outro livro sobre economia primitiva e volta a comentar o ED: destaca a contribuição de Mauss para o estudo da natureza vinculante das obrigaçõos nas trocas primitivas, da coerção social para a retribuição do presente e da rivalidade envolvida nas transações 59 . Desta feita, nem sequer se refere ao hau e não cita a "Introdução" de 1950. Ainda nos anos 1950, Edmund Leach ${ }^{60}$ escreve uma resenha da tradução do $E D$ para o inglês. Como acompanhava de perto o trabalho de Lévi-Strauss, é pouco provável que desconhecesse a "Introdução". Todavia, não se refere a ela, assim como também não o faz Paul Bohannan em estudo sobre a troca ${ }^{61}$.

Nos anos seguintes à publicação da "Introdução", Claude LéviStrauss não voltou a discutir o ED nem os "erros" de Mauss. Publicou trabalhos importantes, como Tristes trópicos (1954) eAntropologia estrutural (1958), tornou-se referência no pequeno mundo dos antropólogos, sobretudo dos especialistas em parentesco que discutiam sua teoria sobre aliança, e passou a ocupar um lugar central na antropologia francesa ${ }^{62}$. Sua obra fascinava os filósofos, o que certamente 
contribuiu para que também ocupasse lugar central na cena intelectual em seu país ${ }^{63}$. Em 1959 foi eleito para o Collège de France. Nas dependências da instituição criou então o Laboratoire d'Anthropologie Sociale e fundou, em 1961, a revista L'Homme. Tanto o Laboratório como a revista constituíram bases sólidas para difundir seu ponto de vista a respeito da "boa antropologia", como LéviStrauss chegou a definir o seu estruturalismo ${ }^{64}$. Sua fama atravessou o Atlântico: a intelectual nova-iorquina Susan Sontag dedicou-lhe o capítulo de um de seus livros ("Contra a interpretação"), as revistas especializadas e os suplementos literários apresentaram artigos que resenhavam sua obra, e editoras prestigiosas publicaram livros coletivos nos quais antropólogos, filósofos e críticos lhe prestavam homenagem. Foi nesse novo contexto que sua interpretação do $E D$ tornou-se referência para os antropólogos e o interesse pelo trabalho de Mauss ampliou-se de forma notável tanto na França como no mundo anglo-saxão, sobretudo nas décadas de 1960 e 70, momento do auge do estruturalismo.

No final da década de 1960, Victor Karady editava na França pela Minuit três volumes de textos de Marcel Mauss. Do outro lado da Mancha, Raymond Firth já citava o "valioso comentário de LéviStrauss" a respeito do trabalho de Mauss e expressava seu acordo com a crítica ao uso do hau "como explicação da troca" ${ }^{65}$. Insistia, no entanto, retomando os argumentos de 1929, em que Mauss havia errado na interpretação do hau. Em 1970, Marshall Sahlins publica o artigo "The spirit of the gift: une explication de texte", em uma coletânea em homenagem a Lévi-Strauss. Inicia o texto com a seguinte afirmação: "o conceito central do Ensaio sobre o dom é a idéia nativa maori do hau". E acrescenta algumas linhas adiante: "o hau maori é erigido numa explicação geral". O autor refere-se a Lévi-Strauss como um dos críticos da interpretação maussiana do hau (os outros dois sendo Firth e Johansen) e cita a passagem do "erro" 66 . Sahlins estivera vinculado ao Laboratório de Antropologia Social entre 1967 e 1969 , e lá apresentara "os resultados de seu trabalho sobre a reciprocidade entre os Maori e sobre a maneira pela qual Mauss e seus sucessores a haviam compreendido". A relação estabelecida com Lévi-Strauss naquele período parece tê-lo marcado decisivamente: "certos princípios do estruturalismo penetraram a vida intelectual e ao menos a antropologia nunca mais será a mesma", disse ele em entrevista concedida em 1985 à Magazine Littéraire ${ }^{67}$.

Ainda em 1970, escrevendo na Man, principal revista britânica de antropologia, Michel Panoff distingue o ED como "um acontecimento maior na história da teoria antropológica" 68 e cita como evidência a afirmação de Lévi-Strauss, da "Introdução" de 1950, de que Mauss teria sido um precursores do estruturalismo. Dois anos mais tarde, a
[63] Muitojá foi escrito sobre a preeminência de Lévi-Strauss naquele período e o fascínio dos filósofos por seu estruturalismo. Ver a respeito Pierre Bourdieu e Jean-Claude Passeron ("Sociology and philosophy in France since 1945: death and resurrection of a philosophy without subject", Social Reasearch XXXIV(I), 1967), D. Bertholet (Claude LéviStrauss, pp.179-242) e F. Keck (Claude Lévi-Strauss, une introduction. Paris: La Découverte, 2005).

[64] D. Bertholet. Claude LéviStrauss, p. 325 .

[65] "Themes in economic anthropology. A general comment". In: R. Firth (org.). Themes in economic anthropology. Londres: Tavistock Publications,1970 [1967], pp. 24 e 25.

[66] Marshall Sahlins. "The spirit of the gift: une explication de texte". In: Pouillon, J. e Maranda, P. (orgs.). Échanges et communications. Melanges offertsà Claude Lévi-Straussà l'occasion de son anniversaire. Paris: Mouton, 1970.pp.1001-2.

[67] D. Bertholet. Claude LéviStrauss, p. 325 .

[6 8] "Marcel Mauss's The Gift revisited”. Man, vol. 5, n. 1, 1970, p.6o. 
[69] Claude Dubar. "Retour aux textes". L'Arc, n. 48, 1972, p.25.

[7 o ] G.Condominas. "Marcel Mauss et l'homme de terrain". L'Arc, n. 48 , 1972, p. 4.

[71] R. Gasché. "L'Échange héliocentrique". L'Arc, n. 48, 1972, p. 84.

[72] D. Holler. "Malaise dans la sociologie", L'Arc, n.48 1972, p. 61.

[73] Pierre Bourdieu. Le Sens pratique. Paris: Éditions de Minuit,1980, pp. 167-89.

[74] Esquisse d'une théorie de la pratique. Genebra/ Paris: Librairie Droz, 1972 , p. 222.

[75] P. E. Josselin de Jong. "Marcel Mauss et les origines de l'anthropologie structurale hollandaise". L'Homme, 12 (4), 1972, pp. 62-84.

[76] David Parkin. "Exchanging words". In: Kapferer, B. (org.). Transaction and meaning. Direction in the anthropology of exchange and symbolic behaviour. Filadélfia: Institute for the Study of Human Issues, 1976, p. 163.

[77] The Budhist saints of he forest and the cult of amulets. A study in charisma, hagiography, sectarianism, and millennial Budhism. Cambridge: Cambridge University Press, 1993 [1984], p.340.

[7 8 ] L'Abondance des pauvres. Paris: Editions du Seuil, 1984, p. 33 .

[79] Inalienable possessions. The Paradox of keeping-while-giving. Berkeley: University of California Press, 1992, pp. 44-65.

[8 o ] L'énigme du don. Paris: Fayard, 1996, p. 32

[81] "Negative strategies in Melanesia". In: Fardon, R. (org.). Localizing strategies. Regional traditions of ethnographic writing. Edimburgo/ Washington: Scottish Academic Press/ Smithsonian Institution Press, 1990, p. 204.

[8 2] "Exchange",p. 219. revista L'Arc edita um número dedicado a Mauss contendo 13 textos. O ED aí aparece "unanimemente considerado a obra-prima do autor" e revelador do princípio oculto da reciprocidade ${ }^{69}$. A "Introdução" de Lévi-Strauss já é dada como "clássica"70. Dois dos trabalhos incluídos no volume correspondem a seminários feitos pelos autores em cursos, nos quais certamente o ED estava sendo discutido:é o caso do texto de Gasché para um seminário de J. Derrida na École Normale Supérieure $^{71}$ e do trabalho do organizador do volume, Dennis Holler ${ }^{72}$, para um curso de A. Green. Em livro publicado em 1972, Pierre Bourdieu cita a "Introdução" de Lévi-Strauss para criticar-lhe a interpretação a respeito das trocas, especialmente as leis mecânicas que regeriam o ciclo de reciprocidade, e chamar a atenção para o intervalo entre o dom e o contradom e a dimensão de incerteza que cerca as transações aspectos que haveria de explorar posteriormente em sua teoria da prática ${ }^{73}$. Bourdieu menciona as reservas de Lévi-Strauss a Mauss ${ }^{74}$, mas não se posiciona em relação ao suposto erro do autor do ED. Ainda em 1972, L'Homme publica um longo artigo de Josselin de Jong sobre Mauss e as origens da antropologia estrutural holandesa ${ }^{75}$, cujo ponto de partida é a "Introdução" de 1950. Em 1976, o ED seria invocado por Parkin como uma das principais referências do conceito de troca. $\mathrm{O}$ texto então é associado ao princípio da reciprocidade, e a Mauss o autor atribui a percepção de um "sistema de troca cultural, envolvendo mulheres, bens, serviços e mensagens" 76 , em uma evidente confusão entre o $E D$ e os escritos de Lévi-Strauss. Refere-se ainda às críticas a Mauss feitas por Firth em 1929, as quais, por crer estarem amparadas em "trabalho de campo intenso", aceita sem reservas.

A partir da década de 1980, o estruturalismo começou a perder força, mas não a tese de que o $E D$ continha uma explicação mística da troca. Com o tempo, a tese foi sendo enriquecida com a recuperação das críticas de Firth de 1929 e do artigo de Sahlins de 1970 transformado em "clássico", e cristalizou-se em uma espécie de crença coletiva. Tudo o que havia de arbitrário e conjuntural nas interpretações foi se naturalizando. O texto de Mauss e o hau, os Maori, a reciprocidade e a teoria da troca tornaram-se então indissociáveis. Assim, por exemplo, Tambiah refere-se à "formulação mística"77 do $E D$; Guidieri à "noção de hau que domina o Ensaio ${ }^{78}$; Weiner trata o ED como o texto teórico mais famoso e mais controvertido sobre reciprocidade e só o invoca para reanalisar dados maoris79; Godelier afirma que não pode deixar de endossar a crítica de Lévi-Strauss de que o hau, contrariamente ao que pensava Mauss, não pode ser tomado como a explicação da troca $^{80}$; Strathern escreve que Mauss havia encontrado entre os Maori "uma das idéia nativas que procurava" ${ }^{1}$; Carrier resume assim a tese $E D$ no verbete troca: "[nas relações de troca] o objeto dado carrega a identidade do doador, que o donatário adquire com o próprio 
objeto"82; Fournier, o biógrafo, escreve que em sua explicação da troca Mauss havia privilegiado o "poder espiritual das coisas" ${ }^{83}$. Nos últimos trinta anos, o ED foi sendo "maorizado", como se tratasse apenas da Polinésia. Tornou-se reconhecido como "obra-prima", mas marcado indelevelmente por um erro: a mistificação pelo ponto de vista nativo; passou a ser visto como uma teoria, e da reciprocidade, noção que nem sequer havia retido a atenção de Mauss naquele momento; $e$ foi transformado em estudo de economia. Tudo o que nele havia referente ao direito - tema central para Mauss e para o grupo de Durkheim - foi completamente esquecido pelos antropólogos, que se enredaram em querelas sobre o hau e a explicação da troca ${ }^{84}$.

Nem todos os antropólogos que trataram o $E D$ no período compartilharam, no entanto, a crença coletiva em relação à explicação mística. Se observarmos a antropologia social britânica, por exemplo, à exceção de Firth, outras figuras expressivas não a consideraram. Edmund Leach, no livro sobre Lévi-Strauss, nem sequer inclui a "Introdução" na bibliografia do autor. Para tratar do que chama de "argumentos" do antropólogo francês sobre a troca, reporta-se ao estudo de 1949 e os trata como se eles se inscrevessem na mesma linha de pensamento de Mauss e dos funcionalistas britânicos, como Firth ${ }^{85}$. Evans-Pritchard, que conhecera pessoalmente Mauss e tinha por ele um grande apreço, distingue o $E D$ como um dos principais trabalhos do amigo e destaca sua contribuição para a comparação sistemática da troca de presentes e sua função na articulação da ordem social. Essas observações estão inseridas na nota que escreveu sobre Mauss, incluída em livro publicado postumamente ${ }^{86}$. Ainda Mary Douglas ${ }^{87}$, em sua introdução a uma tradução inglesa do $E D$, explora a dimensão interessada dos dons enem sequer faz menção a aspectos místicos. Em trabalho sobreo dom, Jonathan Parry argumenta, contra Sahlins e Lévi-Strauss, que Mauss não oferece uma explicação geral a partir de uma ideologia específica [maori], mas que põe em evidência a indissociabilidade entre pessoas e coisas, presente também nos direitos antigos ${ }^{88}$. A importância desse ponto do $E D$ voltaria a ser destacada pelo mesmo autor em publicação posterior ${ }^{89}$. E fora da Inglaterra haveria outros exemplos a mencionar, como Appadurai ${ }^{\circ \circ}$ e Ekeh ${ }^{91}$.

\section{O ETNÓGRAFO dOS ETNÓgRAFOS}

Passo agora à análise do caso do Diário no sentido estrito de termo (doravante simplesmente Diário), de Malinowski, a fim de testar minhas hipóteses. O livro é composto de duas partes: a primeira apresenta notas escritas entre setembro de 1914 e agosto de 1915, durante a estada do autor em Mailu; a segunda contém notas redigidas entre outubro de 1917 e julho de 1918, quando estava nas ilhas Trobriande-
[83] MarcelMauss, p. 520 .

\begin{abstract}
[84] O artigo de Alain Testart ("Uncertainties of the 'obligation to reciprocate"'. In: W. James e N. J. Allen (orgs.).Marcel Mauss. A centenary tribute. Nova York/ Oxford: Berghahn Books, 1998,pp.97-110) a respeito da obrigação de retribuir é um exemplo eloqüente da amnésia dos antropólogos. Em nenhuma passagem do texto o autor trata essa obrigação como própria do direito primitivo. Uma abordagem distinta da teoria da obrigação em Mauss pode ser encontrada no trabalho de um sociólogo como Vogt ("Obligation and right").
\end{abstract}

[8 5 ] Lévi-Strauss. 4a ed. Londres: Fontana Press, 1996 [1970], p. 121.

[86] E. Evans-Pritchard. History of anthropological thought. Londres/ Boston: Faber and Faber, 1981, pp. 191-2.

[87] “Il n'y a pas de don gratuit. Introduction à l'édition anglaise de l'Essai surle don de Marcel Mauss". La Révue Mauss, n 4, 20 semestre de 1989.

[8 8] "The gift, the Indian gift and the 'Indian gift'". Man, (N. S.) 21, 1986,pp. 453-73.

[89] J. Parry e M. Bloch.Money and the morality of exchange. Cambridge: Cambridge University Press, 1995 [1989],pp.5 e 11.

[9०] A. Appadurai. The social life of things. Commodities in cultural perspective. Cambridge/ Nova York/ Port Chester/ Melbourne/ Sydney: Cambridge University Press, 1990 [1986].

[91] Peter Ekeh. Social exchange theory. The two traditions. Londres: Heinemann Educational Books, 1974. 
[92 ] Ver R. Firth, "Second introduction". In: B. Malinowski.A diary in the strict sense of the term. Stanford: Stanford University Press, 1989 [1967].

[93] "Under the mosquito net", New York Review of Books, vol. 9, n- 4, set. 1967 .
sas.Aí se encontra um repertório de angústia, mal-estar no trabalho de campo, explosões de raiva em relação aos nativos, mas também se vêem notas de método, comentários sobre colegas, notas teóricas, observações sobre os nativos — que atestam sua amizade por eles críticas duras a si mesmo e sobre suas relações com as mulheres, suas fraquezas e seus desejos. Ao registrar suas reações em um Diário, Malinowski pretendia, e diz isso repetidas vezes, manter o controle de si. Foi por iniciativa da viúva que o manuscrito polonês foi traduzido para o inglês e publicado em 1967. Raymond Firth escreveu uma introdução de oito páginas, na qual adverte os leitores de que se trata de um "documento humano", destinado a tornar-se apenas uma nota de rodapé na história da antropologia.

A publicação do Diário foi recebida com indignação pelos ex-alunos de Malinowski. Em nova introdução para a segunda edição, Raymond Firth confessa explicitamente o desconforto ao escrever a primeira e revela as reações que tiveram em privado Hortense Powdermarker, Phyllis Kaberra e Lucy Mair, os quais lhe reprovaram duramente por haver dado consentimento implícito à publicação, ao escrever a "Introdução": temiam eles que os já hostis a Malinowski se servissem do Diário para atacá-lo. Em uma carta endereçada a Firth em maio de 1967, Audrey Richards lhe dizia que Hortense Powdermarker já detectava certa irritação entre os americanos, especialmente com relação ao emprego do termo nigger para falar dos nativos, às referências à raiva que Malinowski sentira por eles e ao tempo passado entre os europeus. Em resenha publicada no jornal britânico The Guardian, Edmund Leach, que também fora aluno de Malinowski, condenou a publicação do Diário e enfatizou que a palavra polonesa nigrami não deveria ter sido traduzida como nigger, erro quelevava Malinowski a ser visto como racista ${ }^{92}$.

Os receios de Hortense Powdermaker tinham fundamento. Em setembro de 1967, a New York Review of Books, prestigiosa revista literária norte-americana, publicou uma resenha devastadora escrita por Clifford Geertz ${ }^{93}$. O Diário é apresentado como o derradeiro golpe desferido contra o "mito" Malinowski: pesquisador que em seu trabalho de campo tinha empatia extraordinária com os nativos. O método do autor dosArgonautas é questionado: sua conduta no campo, particularmente as explosões de raiva, revelava falta de empatia; e tal conduta não fazia jus àquela que o próprio definia como apropriada para um pesquisador. Geertz não diz, no entanto, onde, em sua obra, Malinowski havia firmado a empatia como essência de seu método.

No momento em que a resenha fora publicada, Geertz tinha 41 anos e ocupava uma das cadeiras do Departamento de Antropologia da Universidade de Chicago. Iniciara os estudos universitários como aluno de letras, seguindo depois o curso de filosofia. Em 1949, tendo 
terminado a formação universitária, seguiu os conselhos de um professor e decidiu estudar antropologia; então foi fazer o doutorado na Universidade de Harvard, onde Talcott Parsons criara o Department of Social Relations, empreendimento interdisciplinar que marcaria a sociologia dos Estados Unidos na década de 1950. Em 1967, Geertz já fizera trabalho de campo na Indonésia (Bali e Java) e no Marrocos; publicara artigos e livros; ensinara em Berkeley durante um ano; estivera no Center for Advanced Studies in the Behavioral Sciences em Palo Alto, onde entrara em contato com alguns grandes "nomes" das ciências humanas, entre os quais o sociólogo Edward Shills, o cientista político David Apter, o antropólogo britânico Meyer Fortes e o lingüista Roman Jakobson. Shills e Apter o convidaram a participar de outro projeto interdisciplinar na Universidade de Chicago: o Committee for the Comparative Studies of New Nations, cujo objetivo era estudar as transformações sociais desencadeadas pelo desmantelamento dos impérios coloniais 94 .

A resenha de Geertz se inscrevia nas disputas que opunham os antropólogos dos Estados Unidos a seus colegas na Inglaterra em relação ao modo de fazer antropologia: privilegiar a cultura que, desde Talcott Parsons, era compreendida entre os americanos como o universo dos valores e símbolos, ou privilegiar as relações sociais, como preferiam os antropólogos britânicos. Desde sua chegada a Chicago, Geertz e David Schneider, bem como outros jovens antropólogos, dedicavam-se a modificar o ensino de antropologia na universidade.A pretensão deles era descartar a herança estrutural-funcionalista $e$ redefinir a antropologia como o estudo da cultura95. Em 1963, Geertz foi convidado, junto de Marshall Sahlins, Eric Wolf e David Schnneider, a apresentar o ponto de vista americano em uma reunião da Association of Social Anthropologists (ASA), que ocorreria na Universidade de Cambridge. Nessa ocasião, criticou duramente seus colegas europeus, os quais considerava parados no tempo, incapazes de qualquer renovação teórica. Geertz questionou em especial o modo como seconduziam os estudos sobre religião, principalmente por se relacionar a outras dimensões da vida social, e exprimiu seu ponto de vista segundo o qual a religião deveria ser estudada como uma ideologia ${ }^{96}$. Na platéia encontravam-se, entre outros, Edmund Leach, Max Gluckman, Jack Goody, Audrey Richards, Raymond Firth, Meyer Fortes, todos formados direta ou indiretamente por Malinowski. Não obstante os conflitos pessoais, todos ali se reconheciam no método do mestre. Nas notas que fez nessa ocasião, Goody 97 registrou suas reservas em relação a essa nova maneira de fazer antropologia e enfatizou que, para fazer avançar a teoria, são necessários dados e modelos a fim de analisá-los, o que correspondia às lições de Malinowski. A publicação do Diário deu a Geertz a oportunidade de lançar um novo ataque a
[94] Para os dados biográficos de Geertz, usei Handler ("An interview with Clifford Geertz". Current Anthropology, 32 (5), 1991, p. 607), Geertz (Afterthefact. Two countries, fourdecades, one anthropologist.Cambridge (Mass.): Harvard University Press, 1995) e Kuper (Culture. The anthropologists' account.Cambridge (Mass.)/Londres: Harvard University Press, 1999).

[95] R. Handler. "An interview with Clifford Geertz", p. 607, e David Schneider,Schneider on Schneider. The Conversionof the Jews and other Anthropological Stories. Durham e Londres, Duke University Press, 1995 , pp. 174-191.

[9 6] Geertz desenvolveu essas idéias no artigo "Religion as a cultural system". In:M.Banton (org.).Anthropological approaches to the study of religion. Londres: Tavistock Publications, 1973 [1966], pp.1-46.

[97] The expansive moment. Cambridge: Cambridge University Press, 1995, pp. 146-8. 
[98] A. Kuper. Culture.

[99] The interpretation of cultures. Basic Books, 1973, pp. 5-6.

[100]"Baloma, The Spirits of the Dead in the Trobriand Islands", Magic, Science and Religion. Garden City, Nova York: Doubleday Anchor Books, 1955[1916].

[ $\left.\begin{array}{lll}1 & 0 & 1\end{array}\right]$ Local knowledge. Further essays in interpretive anthropology. NovaYork: Basic Books, 1983, pp. 56-7. seus colegas de além-mar ao desacreditar o homem que havia inventado a antropologia social britânica.

Em 1970, Geertz foi convidado a ser o primeiro professor da School of Social Sciences, recém-criada na prestigiosa Universidade de Princeton no quadro do Institute for Advanced Studies. Àquela altura, ele já era um "nome" da antropologia americana e tinha trunfos importantes: fora aluno de Talcott Parsons, o que contava no mundo acadêmico americano, como assinala Kuper ${ }^{8}$, mesmo em um contexto de declínio do modelo parsoniano; e acumulara capital social graças à sorte que tivera de estar nos lugares estratégicos no momento certo, como em Harvard, Palo Alto e Chicago entre as décadas de 1950 e 1960.

Em 1973, Geertz publicou seu manifesto em favor de uma antropologia interpretativa. O propósito da disciplina, segundo ele, era a interpretação dos símbolos da "cultura". As relações sociais em nada interessavam. Fazer antropologia é então definido como fazer etnografia,e esta, por sua vez, consiste em uma "descrição densa"99. Tal concepção representava uma ruptura, não assinalada por Geertz, com o ponto de vista de Malinowski, para quem a etnografia era um método, como fica claro em "Baloma"100, Argonauts of Western Pacific e Coral gardens. Em 1983, Geertz voltou a tratar do Diário. O "problema" do texto, ao contrário do que muitos haviam apontado, não era de ordem moral, mas epistemológica. O Diário tinha sido para a antropologia o equivalente à descoberta da estrutura do DNA para a biofísica, pois tornara inverossímeis as narrativas sobre o modo de trabalho dos antropólogos. "O mito do pesquisador camaleão, perfeitamente afinado com seu entorno exótico, um milagre ambulante de empatia, tato, paciência e cosmopolitismo, foi demolido pelo homem que talvez tenha mais feito para criá-lo"101. Geertz continuava a se apoiar nos dois supostos da resenha de 1967: o de que o Diário revelava ausência de empatia, e o de que a empatia constituía o núcleo do método de Malinowski. O autor formula então a seguinte pergunta: se o conhecimento do ponto de vista dos nativos não depende da empatia, como então ele seria possível? A solução seria o estudo das formas simbólicas: as palavras, as imagens, as instituições e os comportamentos. Os comentários servem de preâmbulo a uma análise sobre as concepções de pessoa em Bali, Java e no Marrocos. O modo como as apresenta e as interpreta permite perceber a distância que o separava do "mito". Para Malinowski, descrever e interpretar crenças eram tarefas complexas. Como mostra à exaustão nas mais de cem páginas de "Baloma", o problema residia em como identificar as crenças. Para Geertz, tal questão nem sequer se colocava: ele não explica ao leitor como chegou às crenças nativas, tampouco leva em conta a diversidade interna e as diferentes competências para falar sobre as crenças, que tanto preocupavam 
Malinowski ${ }^{102}$. A diferença não residia, portanto, na empatia, jamais invocada por este como recomendação de método, mas na natureza das questões formuladas. Em Geertz, a questão consistia em interpretar significados, tarefa que propõe que ser realizada da mesma forma como se interpreta um texto ou um poema ${ }^{103}$.

Em 1988, Geertz retorna uma vez mais à publicação de 1967, nos quadros de uma discussão sobre a credibilidade dos textos dos antropólogos ${ }^{104}$. Defende então a tese de que a credibilidade se deve à capacidade de "convencer" que os autores possuem e de que o convencimento é por eles logrado mediante o recurso a procedimentos literários, ao estilo e ao fato de terem estado "lá", no campo. Malinowski é apresentado como o herói que foi abatido por seu Diário, mas Geertz não lhe recusa o crédito de ter convencido bem seus leitores a propósito do kula e lhe confere o epíteto de "etnógrafo dos etnógrafos". Não são levadas em conta as recomendações metodológicas de Malinowski, como a conduta no trabalho de campo, o recolhimento de dados, a elaboração de explicações, quadros e diagramas, a tomada de notas, o teste das hipóteses - que se encontram nos textos de caráter metodológico e no próprio Diário ${ }^{105}$. Para Geertz, as atividades do antropólogo em campo não interessam: o que importa éo modo como narra a experiência. O Diário serve de argumento para evidenciar a distância entre a experiência subjetiva no campo e os escritos acadêmicos. Se Malinowski teve êxito ao estabelecer o vínculo entre o trabalho de campo e a escrita, isso se deve a recursos literários; se os leitores se convencem, isso não se deve aos "fatos" apresentados.

As escolhas teóricas de Geertz têm relação com a herança parsoniana (a cultura vista como esfera autônoma) e com a aproximação, nos Estados Unidos, entre a antropologia, a filosofia e os estudos literários, como mostra Kuper ${ }^{106}$. Não se trata aqui de discutir esses escritos, mas de examinar o lugar do Diário neles. Malinowski foi e continua a ser referência obrigatória na disciplina. A despeito das críticas às suas supostas "falhas" teóricas e de tudo o que foi dito sobre o Diário, é um autor incontornável sempre que se trata de ensinar às novas gerações o ofício de antropólogo; sua monografia sobre o kula é tida como etnografia exemplar. Mesmo aqueles que desejam fazer uma "revolução" são constrangidos a prestar-lhe homenagem. É o caso de Geertz, que acreditou encontrar no texto de 1967 uma espécie de face oculta da etnografia e disso se serviu para avançar suas proposições sobre o deverser do ofício de antropólogo.

Desde a década de 1980, Geertz se tornou um personagem central na antropologia dos Estados Unidos ${ }^{107}$ : foi reconhecido como o responsável pela renovação da disciplina ${ }^{108}$ e como o antropólogo mais influente fora do círculo dos pares ${ }^{109}$. Suas proposições relativas à antropologia como interpretação de significados, à cultura como um derava que o domínio da língua era condição necessária para compreender o ponto de vista nativo, Geertz não se preocupava com isso: analisou a noção de pessoa entre os balineses sem conhecer a língua deles. Quando Handler lhe indagou, na entrevista publicada em 1991, se o trabalho de campo em Bali havia implicado o aprendizado da língua, respondeu: "Não, jamais aprendi bem o balinês".

[1 $\left.\mathrm{lO}_{3}\right]$ C. Geertz, Local knowledge, p. 70 .

[104] C. Geertz, Works and Lives. The Anthropologist as Author. Stanford: Stanford University Press, 1988.

[1 0 0 5 ] Em artigo sobre a importância dos procedimentos burocráticos nas etnografias de alguns antropólogos, Kenneth Dauber ("Bureaucratizing the etnographer's magic". Current Anthropology, 36 (1), 1995, pp. 75-95) analisa o caso de Malinowski e chama a atenção para a preocupação com os registros precisos, valendo-se para tanto também do Diário.

[1 0 6]A. Kuper. Culture.

[1 107 7 Ver A. Kuper, Culture, p. 118, e "Alternative histories of British social anthropology", p. 61 (Social Anthropology, 13(1), 2005).

[ 10 o 8 ] Sherry Ortner (org.). The fate of 'Culture'. Geertz and beyond. Berkeley/Londres: University of California Press, 1999, pp. 1-13.

[1 0 o $]$ ]W. H. Sewell Jr. “Geertz, cultural history: From synchrony to transformation". In: Sherry Ortner (org.). The fate of 'Culture', p. 35. 
[110] George Marcus e Dick Cushman. "Etnographies as texts".Annual Review of Anthropology, n. 11, 1982, pp. 25-69; George Marcus and Michael M. J. Fischer (orgs.). Anthropology as cultural critique. An experimental moment in the human sciences. Chicago/ Londres: The University of Chicago Press, 1986;. James Clifford e George Marcus. Writing culture. The poetics and politics of ethnography. Berkeley (LA)/ Londres: 1986; James Clifford. The predicament of culture. Cambridge (Mass.)/ Londres: Harvard Univesity Press, 1988; Sherry Ortner (org.). The fate of 'Culture', 1999; R. Rosaldo. Culture and truth. The remaking of social analysis. Boston, 1999. Encontra-se uma análise fina da importância de Geertz como fonte de inspiração para a nova geração em Kuper (Culture,pp. 201-25).

[111] "The ethnographer's magic". In: The ethnographer's magic and other essays in the history of social anthropo$\operatorname{logy}$. Chicago: The University of Wisconsin Press, 1983, pp. 12-59.
[1 112$]$ "Further reflections on Lesu and Malinowski's Diary". Oceania, vol. 40, 1970, pp.346-7.

[113] Antropólogos e antropologia. Rio de Janeiro: Francisco Alves Editora, 1978 [1973].

[114] J. Urry. Before social anthropology: Essays on the history of British social anthropology. Chur (Suíça). Harwood Academic Press, 1993.

[115] Malinowski. Odyssey of an anthropologist: 1884-1920. New Haven/ Londres: Yale University Press, 2004 texto; suas discussões sobre a escrita e a credibilidade dos textos antropológicos; sua defesa da ruptura das fronteiras entre a antropologia, a filosofia e a crítica literária, e sua ênfase na preeminência da experiência subjetiva do antropólogo no campo tornaram-se fonte de inspiração para a nova geração de antropólogos norte-americanos, como Marcus, Cushman, Fischer, Clifford, Ortner e Rosaldo ${ }^{110}$. Os debates relativos à natureza da etnografia, inaugurados por Geertz, apaixonam os jovens praticantes, que dedicam longos textos à exegese do trabalho de campo, à escrita antropológica e ao caráter experimental da etnografia. Os procedimentos do antropólogo em campo para constituir seu corpus de análise não são objeto de debate e passam a ser associados ao "realismo" da antropologia social britânica, um paradigma que decretam superado. Nesse contexto o Diário de Malinowski é freqüentemente invocado como um documento que atestaria a incongruência entre a experiência subjetiva e as exigências de rigor metodológico e cuja publicação teria desencadeado uma revolução na disciplina. Nas referências ao Diário, nem sempre Geertz era citado: suas interpretações sobre o texto e seus veredictos a respeito das implicações para a etnografia já eram, nos anos 1980, uma doxa entre os antropólogos nos Estados Unidos. Para os historiadores da antropologia, a etnografia e o Diário se tornaram um problema. Assim, George Stocking ${ }^{111}$ propôs-se a historicizar o trabalho de campo de Bronislaw Malinowski. O Diário foi tomado como fonte, mas o ponto de partida era a problemática da "empatia", do mito Malinowski, da "desmistificação do herói" e da experiência no campo, questões caras a Geertz desde 1967.

No resto do mundo anglo-saxão, o Diário não foi tratado do mesmo modo. Assim, em 1970, Hortense Powdermaker observa que Malinowski jamais afirmara, nem nos escritos nem nos cursos, ter empatia com os nativos: isso não fazia parte das recomendações muito precisas que dava a seus alunos que partiam para o campo ${ }^{112}$; Adam Kuper, em sua história da antropologia social britânica, volta ao Diário, mas para evidenciar o modo como Malinowski trabalhava no campo e sua "enorme criatividade"113; Urry, antropólogo australiano, em sua história da antropologia britânica, faz referência ao texto de 1967 para assinalar as recomendações metodológicas do autor ${ }^{114}$; e, mais recentemente, Michael Young, o biógrafo, serve-se largamente do texto de 1967 para reconstituir a estada de Malinowski no campo e estabelecer relação entre os dados do Diário e outras fontes ${ }^{115}$. Outros grandes nomes da antropologia norte-americana, como Marshall Sahlins, Eric Wolf e Sydney Mintz, não se engajaram na nova definição de antropologia proposta por Geertz, mas foi o ponto de vista do último que prevaleceu. A associação que estabeleceu entre antropologia, etnografia e experiência é,em nossos dias, a interpretação hegemônica nos Estados Unidos. 
No decorrer da análise, destaquei, por um lado, Lévi-Strauss, porque foi a partir de seus escritos que se produziu a inflexão na leitura do texto de Mauss, e, por outro, Clifford Geertz, cujo modo de tratar o Diário foi o que se impôs como dominante. Para os dois casos foi possível formular hipóteses a respeito do que poderia estar em jogo em suas interpretações no contexto em que foram formuladas: para LéviStrauss, em um primeiro momento filiar-se a Mauss para ser aceito por seus pares na França, e dele se distinguir por meio da indicação do erro para fazer avançar sua própria teoria e sua própria carreira; para Geertz, em um primeiro momento demolir Malinowski no âmbito da concorrência com os antropólogos britânicos e depois utilizá-lo para legitimar uma nova definição do ofício de antropólogo. Uma vez elaboradas, suas interpretações sobre o ED e o Diário, como quaisquer outras, eram somente novas mercadorias a circular no mercado das idéias. O crédito atribuído a seus escritos esteve intimamente relacionado à ascensão de nossos dois personagens na hierarquia de prestígio dentro e fora do mundo dos antropólogos. Foi o capital científico, essa "espécie particular do capital simbólico, fundada sobre o conhecimento e o reconhecimento" 116 , que lhes proporcionou tanto a atenção para seus escritos como a crença na justeza de suas interpretações.

No que diz respeito ao $E D$, os primeiros antropólogos a atribuírem crédito a Lévi-Strauss foram Raymond Firth e Marshall Sahlins. Não pertenciam à mesma geração, mas tinham propriedades em comum: ambos trabalhavam sobre temas como a economia, as trocas e o Pacífico Sul. Além disso, a argumentação da "Introdução" se apoiava em passagens do ED referentes aos Maori, povo que os dois tinham estudado. Compreende-se então por que os comentários de Lévi-Strauss chamaram a atenção deles e por que eles, e não os especialistas de outras províncias etnográficas, foram os propagadores da interpretação de 1950.Lévi-Strauss era, desde os anos 1950, um interlocutor privilegiado dos antropólogos nos debates sobre parentesco, à época tema nobre da disciplina. A "Introdução" permitiu que os outsiders das disputas sobre aliança e filiação, como Firth e Sahlins, viessem a também participar das discussões com a obra daquele que era o farol da disciplina. Firth e Sahlins já tinham então um "nome", eram antropólogos reconhecidos e professores de dois dos principais centros de ensino da disciplina: a London School of Economics e a Universidade de Chicago. O prestígio pessoal e o prestígio das instituições às quais estavam vinculados garantiram que o aval dado por ambos à interpretação de 1950 tivesse acolhida favorável.

No caso do Diário, foram os jovens antropólogos, alguns deles exalunos de Geertz, como Sherry Ortner, que levaram adiante a boa-
[116] Science de la science et réflexivité. Paris: Éditions Raison d'Agir, 2001, p. 70. 
[117] A. Kuper. "Alternative histories of British social anthropology".

[1 18 ] O modo como Lévi-Strauss e Geertz lidaram com os textos de Mauss e Malinowski foi semelhante. Nos dois casos não há referência às páginas para o leitor conferir o que está sendo dito.Ambos os intérpretes consideram que os textos em questão desencadearam verdadeiras revoluções na disciplina. Assim, o ED teria aberto "uma nova era para as ciências sociais" e sua importância para a antropologia seria equivalente àquela da descoberta da análise combinatória para a matemática moderna. Para Geertz, o Diário seria o equivalente em antropologia à descoberta do DNA. Haveria aproximações a serem feitas entre esse modo de proceder e aquele corrente entre profetas e mágicos, mas não há espaço aqui neste artigo para explorar esses pontos.

[119] Norbert Elias e John L. Scotson. The established and the outsiders. A sociological enquiry into community problems. Londres/ Nova Delhi: Thousand Oaks/ Sage Publications, $1994[1965]$. nova do mestre. Desejando participar da "revolução" simbólica promovida pelo grande "nome" da antropologia, eles trataram de reproduzir os pontos de vistas de Geertz, dentre eles o que dizia respeito a Malinowski.À medida que os jovens também passaram a ocupar posições importantes no mundo universitário norte-americano e a fazer "nome", lograram obter uma enorme audiência para seus escritos dentro e fora do país. O declínio da antropologia social britânica e a ascensão da antropologia cultural norte-americana a partir dos anos $1970^{117}$ foram certamente decisivos para que esses jovens antropólogos se impusessem no campo da antropologia.

Nos dois casos em exame, não houve por parte dos difusores das interpretações a preocupação de ir nem ao $E D$ nem ao Diário para verificar a pertinência das interpretações. As palavras de Lévi-Strauss e de Geertz foram tratadas como palavras autorizadas, como se o prestígio dos dois eminentes antropólogos constituísse por si uma garantia do fundamento de suas afirmações ${ }^{118}$. Afinal, como alertava Max Weber no trecho citado no início deste artigo, seria difícil "pensarque um professor universitário pudesse se enganar completamente sobre a questão em debate". A mesma observação vale para os antropólogos que, em diferentes tradições nacionais, não se indagam sobre a pertinência das interpretações a respeito de Mauss e Malinowski. Também eles acreditam na palavra emitida pelos "grandes nomes"; eles crêem.

A dinâmica da instauração de uma doxa é entretida por essa crença e pelo modo de funcionamento do mundo acadêmico. Nesse mundo, os indivíduos desejam adquirir um "nome", ser escutados e reconhecidos como membros plenos. A via clássica e menos arriscada para atingir tal objetivo éaliar-se ao mainstream, seguir os grandes "nomes". Em antropologia, isso se faz sem muitos problemas: basta enquadrarse em um esquema teórico e assinalar a própria singularidade pelo viés de sua etnografia. Essa abordagem garante, ao mesmo tempo, a escuta dos crentes ao "grande nome" e o reconhecimento como especialista legitimado pelo "trabalho de campo" (um "nome"). Tal modo de funcionamento contribui para que as interpretações daqueles cujo carisma é reconhecido sejam consideradas evidentes por si mesmas. Mas é possível ir além e tentar compreender a dinâmica da doxa. A comparação com o fluxo de intrigas (gossip) em Winston Parva, comunidade estudada por Elias e Scotson ${ }^{119}$, não nos afastará demasiado do assunto. Como observam os autores, a participação nas intrigas de admiração (praise gossip) e nas intrigas de acusação (blame gossip) em relação aos outsiders garante aos estabelecidos o sentimento de pertencer ao grupo - eles se sentem por isso compelidos a tomar parte no jogo de intrigas:é o preço a pagar para usufruir dos privilégios do establishment. Um dos elementos determinantes da intriga é o grau de concorrência para ser escutado. É possível avançar a hipótese de que a 
reprodução das interpretações de Lévi-Strauss e de Geertz faria parte das intrigas de admiração; a associação do ED a "aspectos místicos" e a associação do Diário à destruição do "mito" e seu método fariam parte das intrigas de acusação. Valorizar uns e criticar outros era condição necessária para se fazer entender, ou, como sugere Randall Collins ${ }^{120}$, para atrair a atenção e ser aceito como membro pleno de uma comunidade - aqui, a comunidades dos antropólogos. Como em Winston Parva, aqueles que desejavam ser reconhecidos como membros eram submetidos a coerções; estas, no entanto, não eram percebidas como tais - é o observador quem as vê. Em um mundo como o acadêmico, no qual se crê na liberdade dos indivíduos e na virtude das idéias, não surpreende que os indivíduos pensem a reprodução de um ponto de vista simplesmente como produto da livre escolha intelectual da melhor idéia no mercado.

Ao longo deste texto, procurei indicar a existência de antropólogos que, no período estudado, trataram diferentemente o ED e o Diário e nem sequer levaram em conta as interpretações de Lévi-Strauss e Geertz. Esses casos levantam uma nova gama de questões - como a do alcance das redes de intrigas e a das outras modalidades de constituir um "nome" (como a heresia) - , que vão além dos objetivos deste trabalho. Tentei aqui simplesmente tornar inteligíveis os fundamentos das crenças coletivas em uma certa interpretação e a dinâmica de uma doxa. Para isso, levei em conta o lugar das ambições pessoais na produção dos veredictos sobre os autores, as relações entre carisma e crença e os efeitos das coerções sofridas para ser escutado - dimensões freqüentemente negligenciadas nas análises encantadas da repercussão das obras. Não era o caso de questionar as obras ou a importância das contribuições de Lévi-Strauss, Geertz ou outros personagens aqui invocados à teoria antropológica, mas de compreender o ponto de vista deles e sua influência. Desenvolvi minha análise com base nos casos do ED e do Diário - e poderia proceder a partir de diversos outros que apresentam características semelhantes — como propósito de oferecer pistas para a análise da "força" das idéias.

LYGIA SIGAUD é professora associada do Departamento de Antropologia do Museu Nacional (UFRJ) e bolsista do CNPq e da Faperj.
[1 20$]$ The sociology of philosophies. A global theory of intellectual change. Cambridge (Mass.)/ Londres: The Belknap Press of Harvard University Press, 1988, pp.38-9.

Recebido para publicação em 7 de fevereiro de 2007.

\section{NOVOS ESTUDOS}

CEBRAP

77 , março 2007

pp. 129-152 